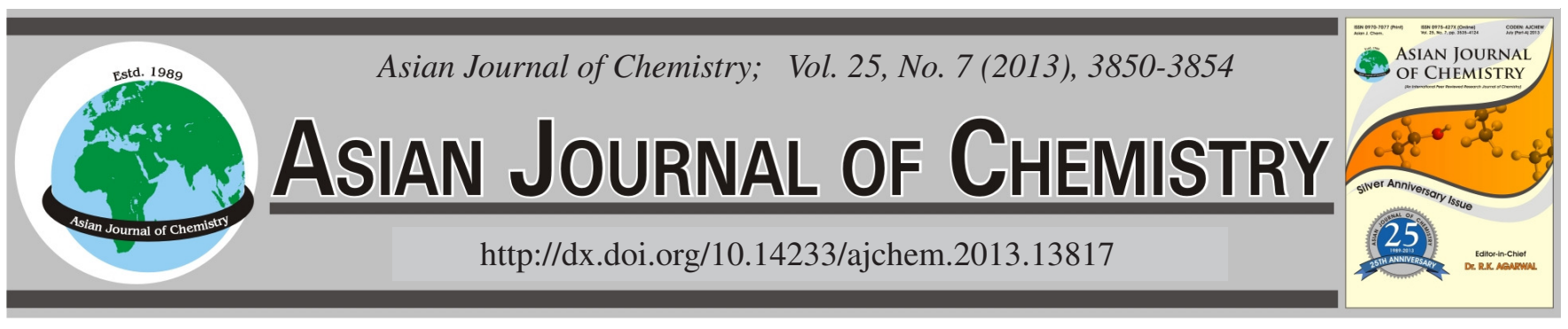

\title{
Ammonium Nitrogen Adsorption-Desorption Characteristics and Its Hysteresis of Typical Soils from Guanzhong Basin, China
}

\author{
Lei Duan*, Wen-Ke Wang and Yaqiao Sun
}

School of Environmental Science and Engineering, Chang'an University, Xi'an 710054, Shaanxi Province, P.R. China

*Corresponding author: Fax: +86 29 85585485; Tel: +86 29 82339957; E-mail: duanlei1978@126.com

\begin{abstract}
The adsorption-desorption characteristics and desorption hysteresis of ammonium nitrogen were studied in typical soil collected from the Guanzhong Basin. The effects of soil texture, $\mathrm{pH}$ and temperature on adsorption-desorption ammonium nitrogen were also discussed. The results showed that the Langmuir model fitted the adsorption of clay and fine sand and the Henry model fitted the adsorption of silty clay and silty sand. The Langmuir Ext1 model fitted desorption of clay and the Henry model fitted desorption of others three soils. The values of desorption rate for clay, silty clay, silty sand and fine sand been 10, 28, 43 and $66 \%$ in sequence. The content of clay minerals and organics were positively correlated with the adsorption of ammonium nitrogen. The ammonium nitrogen adsorption by four soils all increased as solution $\mathrm{pH}$ increased. The effect of temperature on the ammonium nitrogen adsorption was more significant than the capacity desorption.
\end{abstract}

Key Words: Adsorption-desorption, Characteristics, Hysteresis, Ammonium nitrogen.

\section{INTRODUCTION}

The generality and university of agricultural nonpoint source pollution in water environment are given much attention $^{1,2}$. Rapid development of industry and agriculture is increasing the environment contamination in these areas with intensive industrial and agricultural activities result in increased use of pesticides and fertilizers ${ }^{3-6}$ and increased use of wastewater irrigation ${ }^{7-9}$. These activities resulted in increased nitrogen contamination of groundwater. The nitrate nitrogen, ammonium nitrogen and others contained nitrogen compounds, which are mainly caused by agricultural nonpoint source pollution, are increasing the potential threat to human health in those countries and regions with the groundwater as the main drinkable water source ${ }^{10,11}$. So, the transport and transformation process of nitrogen in soil and groundwater has been a critical environmental issue.

Adsorption of ammonium nitrogen in soils and sediment has been widely studied using batch experiment and soil column experiment to explore absorbance, absorption mode and absorption mechanism, etc. ${ }^{11-16}$. Among these methods, the transport and transformation characteristics of ammonium nitrogen in different type soils are well analyzed under certain aeration soil column experiment ${ }^{17-19}$. The adsorption-desorption dynamics and thermodynamics action of ammonium nitrogen in soils were explained by batch experiments about ammonium nitrogen $^{20-22}$. On the other hand, few information is available about desorption and hysteresis of ammonium nitrogen in soils under either laboratory or field conditions.

There are many factors that influence adsorption-desorption of ammonium nitrogen in soils, including soil texture, structure, mineral composition, moisture content, temperature and other environmental elements. So, the adsorption-desorption process of ammonium nitrogen in different type soils present some variability.

Thus, the objectives of this study were to analyze the adsorption-desorption characteristics and hysteresis of ammonium nitrogen on typical Guan zhong basin soils and to explain the influence of soil texture, $\mathrm{pH}$ and temperature on its isothermal adsorption-desorption for ascertaining the migration and transformation mechanism of ammonium nitrogen in the environment.

\section{EXPERIMENTAL}

Soil samples: Fine sand, silty sand, silty clay and clay, four typical soils in Guanzhong Basin China, were used in this study. They are taken from flood plain, first terrace, second terrace and clay table land, respectively. Soil samples were collected from the surface layer $(0-20 \mathrm{~cm}$ depth), air-dried and sieved through a 2-mm nylon-fiber sieve and stored in a dark place at room temperature prior to use. The physicochemical properties of the soils are given in the Table- 1 . 
TABLE-1

PHYSICOCHEMINCAL PROPERTIES OF THE TESTED CHINESE SOILS

\begin{tabular}{|c|c|c|c|c|c|c|c|c|c|c|c|}
\hline Soil & $\mathrm{pH}$ & $\begin{array}{c}\mathrm{Ca}^{2+} \\
(\mathrm{mg} / \mathrm{kg})\end{array}$ & $\begin{array}{c}\mathrm{Mg}^{2+} \\
(\mathrm{mg} / \mathrm{kg})\end{array}$ & $\begin{array}{c}\mathrm{Cl}^{-} \\
(\mathrm{mg} / \mathrm{kg})\end{array}$ & $\begin{array}{c}\mathrm{SO}_{4}{ }^{2-} \\
(\mathrm{mg} / \mathrm{kg})\end{array}$ & $\begin{array}{c}\mathrm{HCO}_{3}^{-} \\
(\mathrm{mg} / \mathrm{kg})\end{array}$ & $\begin{array}{c}\mathrm{NH}_{4}^{+} \\
(\mathrm{mg} / \mathrm{kg})\end{array}$ & $\begin{array}{c}\mathrm{NO}_{2}^{-} \\
(\mathrm{mg} / \mathrm{kg})\end{array}$ & $\begin{array}{c}\mathrm{NO}_{3}^{-} \\
(\mathrm{mg} / \mathrm{kg})\end{array}$ & $\begin{array}{c}\text { Organic } \\
\text { matter }(\mathrm{g} / \mathrm{kg})\end{array}$ & $\begin{array}{c}\text { Moisture } \\
\text { Content (\%) }\end{array}$ \\
\hline Clay & 7.65 & 243.14 & 21.16 & 44.31 & 554.67 & 126.87 & 2.28 & 0.97 & 31.36 & 56.54 & 16.6 \\
\hline Silty clay & 8.17 & 180.14 & 70.23 & 59.5 & 273 & 171.79 & 2.56 & 2.51 & 84.61 & 47.08 & 17.54 \\
\hline Silty sand & 8.2 & 271.43 & 30.21 & 89.3 & 329.25 & 115.36 & 6.35 & 1.44 & 107.83 & 29.44 & 23.2 \\
\hline Fine sand & 8.1 & 121.31 & 18.29 & 40.61 & 113.45 & 201.34 & 1.35 & 0.31 & 12.29 & 10.0 & 21.3 \\
\hline
\end{tabular}

Absorption-desorption experiments procedure: Isothermal absorption-desorption experiments were carried out under the guidance of the standard batch equilibration method $^{23}$. In ten samples of $5 \mathrm{~g}$ of four air-dried soils and 100 $\mathrm{mL}$ of aqueous solution of ammonium nitrogen at concentrations of $0,5,10,20,40,60,100,120,150$ and $200 \mu \mathrm{g} / \mathrm{mL}$ were added to $250 \mathrm{~mL}$ brown conical flask, respectively. The conical flasks were oscillated for $24 \mathrm{~h}$ at $(25 \pm 2)^{\circ} \mathrm{C}$ using a oscillator. After equilibrium, the samples were centrifuged at $2500 \mathrm{r} / \mathrm{min}$ for $30 \mathrm{~min}$ and then the supernatant solutions were decanted and analyzed immediately by Nessler's colourimetry. The amount of ammonium nitrogen absorbed by each soil $\left(\mathrm{S}_{\mathrm{a}}\right)$ was calculated from the difference initial and final concentrations of ammonium nitrogen in solution.

After the adsorption process described above, the supernatant solution was withdrawn. The remaining slurry was again added in $100 \mathrm{~mL}$ distilled water, oscillated equilibrium for 24 $h$, centrifuged, measured and calculated the desorption $\left(S_{d}\right)$.

In addition, the effects of soil solution $\mathrm{pH}$ and temperature on ammonium nitrogen adsorption-desorption were also examined. Prior to the test, the $\mathrm{pH}$ values of ammonium nitrogen solutions were adjusted to $4,6,8,10$ and 12 with $\mathrm{HCl}$ or $\mathrm{NaOH}$ and the amount adsorbed was quantified with the same procedure described for natural soils. The temperature were 21,25 and $35^{\circ} \mathrm{C}$. In these studies, 4 types of soils (Fine sand, silty sand, silty clay and clay), representing the different soil $\mathrm{pH}$ value and soil texture, were applied to determine the effect of $\mathrm{pH}$ and temperature on ammonium nitrogen adsorptiondesorption.

\section{RESULTS AND DISCUSSION}

Isothermal adsorption characteristics: The Langmuir model was found to be the most appropriate to fit experimental data and then to describe the ammonium nitrogen adsorption process onto clay and fine sand (Fig. 1). The Henry model could describe the ammonium nitrogen adsorption process onto silty clay and silty sand accurately (Fig. 1).

Fig. 1 shows the ammonium nitrogen adsorption rate of clay and fine sand is relatively important at the beginning of the experiments and thereafter it decreases significantly until equilibrium about $40 \mathrm{mg} / \mathrm{L}$ (the initial concentration of ammonium nitrogen is $79.5 \mathrm{mg} / \mathrm{L}$ ). When the equilibrium concentration is less than $40 \mathrm{mg} / \mathrm{L}$, the soil adsorption on ammonium nitrogen is linear adsorption. On the contrary, when the equilibrium concentration is more than $40 \mathrm{mg} / \mathrm{L}$, the soil adsorption on ammonium nitrogen is nonlinear adsorption and the absorbance tends to a constant, the maximum absorption of clay and fine sand is $983.30 \mathrm{mg} / \mathrm{kg}$ and $588.0 \mathrm{mg} / \mathrm{kg}$, respectively. Based on the fertilizing and irrigation amount average per mu in recent 10 years, the fertilizing concentration of ammonium nitrogen can be estimated as $85 \mathrm{mg} / \mathrm{L}$. The fertilizing concentration is close to ammonium nitrogen linear adsorption concentration $79.5 \mathrm{mg} / \mathrm{L}$, after be deducted $10 \%$ loss in the form of ammonia. So, the clay and fine sand of ammonium nitrogen adsorption process is considered as linear adsorption in study region. The slope of linear equations could be represented clay and fine sand adsorption coefficient, which are $19.92 \mathrm{~L} / \mathrm{kg}$ and $7.99 \mathrm{~L} / \mathrm{kg}$ respectively.

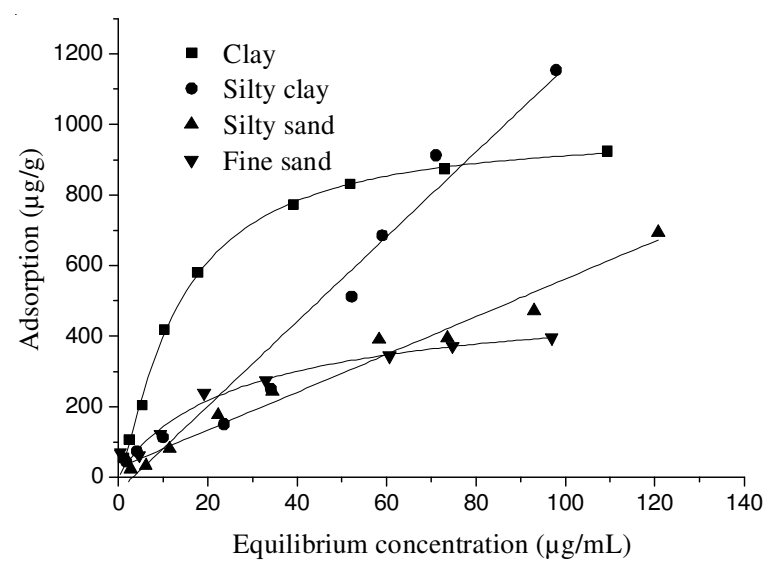

Fig. 1. Adsorption isotherm fitting curve of ammonium nitrogen onto soils

The ammonium nitrogen adsorption data of silty clay and silty sand were well described by the linear equation. The adsorption coefficients of silty clay and silty sand are 12.37 $\mathrm{L} / \mathrm{kg}$ and $5.43 \mathrm{~L} / \mathrm{kg}$ respectively. So, the adsorption coefficient of ammonium nitrogen for four typical mediums follows the sequence clay $>$ silty clay $>$ fine sand $>$ silty sand. Besides, the isothermal adsorption regression lines of the silty sand and silty clay have a nonzero intercept. According to the adsorption-desorption theory, the isothermal adsorption curve intercept of silty clay is less than zero, which means the ammonium nitrogen background value of silty clay is rather high. When the ammonium nitrogen concentration of aqueous solution is less than background value, desorption speed is greater than the adsorption speed and then ammonium nitrogen is discharged into solution from soil. The isothermal adsorption curve nonzero intercept of silty sand is caused by fixed ammonium nitrogen. The adsorbed ammonium nitrogen in sediment was divided into exchangeable and fixed ammonium nitrogen and the nonzero intercept of regression line was created by the content of fixed ammonium nitrogen ${ }^{24}$. Liu et $a l .{ }^{25}$ confirmed this conclusion through the adsorption characteristic analysis of surface sediment on ammonium nitrogen in tidal flat of Yangtze Estuary.

Characterization of isothermal desorption: The ammonium nitrogen desorption data obtained by the dilution method were fitted to nonlinear form. The correlation coefficients $\mathrm{R}^{2}$ for 
the clay, silty clay, silty sand and fine sand are 0.96, 0.99, 0.99 and 0.99 respectively indicated that desorption of ammonium nitrogen had higher correlation coefficients $\left(R^{2}=0.96-0.99\right)$.

The formula of the Langmuir Ext1 model and Henry model and the fitting formula of the Langmuir Ext1 model and Henry model for clay, silty clay, silty sand and fine sand are listed in Table-2. The isothermal desorption curve of ammonium nitrogen of silty clay, silty sand and fine sand were fitted to the Henry model, expect for the clay which the Langmuir Ext1 model fitted better. The isothermal adsorption model can also describe the desorption model of ammonium nitrogen. The Langmuir desorption isotherm of ammonium nitrogen of clay fit linear model when ammonium nitrogen adsorption is less. For the ammonium nitrogen desorption of the clay, the slope of linear fitted equation is 8.71 , so the ammonium nitrogen desorption coefficient for clay is $8.71 \mathrm{~L} / \mathrm{kg}$. According to the isothermal desorption equation of ammonia nitrogen, the maximum desorption amount of ammonium nitrogen is $129.0 \mathrm{mg} / \mathrm{kg}$. For the ammonium nitrogen desorption of the silty clay, silty sand and fine sand, the slope of linear fitted equations are 12.37, 15.07 and 14.09 respectively, so the desorption coefficients of ammonium nitrogen in these three medium are $12.37 \mathrm{~L} / \mathrm{kg}, 15.07 \mathrm{~L} / \mathrm{kg}$ and14.09 $\mathrm{L} / \mathrm{kg}$ in sequence. From the ammonium nitrogen desorption coefficients of above four mediums, the order of desorption coefficients of different medium are silty sand $>$ fine sand $>$ silty clay $>$ clay.

\begin{tabular}{lccc}
\multicolumn{4}{c}{ TABLE-2 } \\
\multicolumn{5}{c}{$\begin{array}{c}\text { DESORPTON FITTING EQUATIONS OF } \\
\text { AMMONIUM NITROGEN }\end{array}$} \\
\hline \multicolumn{1}{c}{ Soil } & Model & $\begin{array}{c}\text { Model } \\
\text { Formula }\end{array}$ & Fitting Formula \\
\hline Clay & $\begin{array}{c}\text { Langmuir } \\
\text { Silty clay }\end{array}$ & $\begin{array}{c}\mathrm{S}_{\mathrm{d}}=\mathrm{S}_{\max } \mathrm{kC}^{1-\mathrm{x}} / \\
\left(1+\mathrm{KC}^{1-\mathrm{x}}\right)\end{array}$ & $\begin{array}{c}\mathrm{S}_{\mathrm{d}}=14.19 \mathrm{kC}^{1.15} / \\
\left(1+\mathrm{kC}^{1.15}\right)\end{array}$ \\
Silty sand & Henry & $\mathrm{S}_{\mathrm{d}}=\mathrm{kC}+\mathrm{q}$ & $\mathrm{S}_{\mathrm{d}}=12.37 \mathrm{C}+7.45$ \\
Fine sand & Henry & $\mathrm{S}_{\mathrm{d}}=\mathrm{kC}+\mathrm{q}$ & $\mathrm{S}_{\mathrm{d}}=15.07 \mathrm{C}+5.87$ \\
\hline
\end{tabular}

Desorption hysteresis of ammonium nitrogen: Fig. 2 shows the desorption hysteresis from isothermal adsorptiondesorption data in the different soils. During these phase, the maximum adsorption capacity of medium is greater than its maximum desorption amount. The ammonium nitrogen desorption capability of clay is the weakest and desorption hysteresis is obvious. But the ammonium nitrogen desorption capability of fine sand is the strongest and desorption hysteresis is weaker. On the other hand, the desorption hysteresis of silty clay and silty sand is between the above both. The study found that desorption equilibrium concentration is around 20 $\mu \mathrm{g} / \mathrm{mL}$.

The desorption process is of great importance to the fate of a pollutant in soils, because it controls the release of a pollutant adsorbed. Desorption rate is often used to describe the reversibility of adsorption and desorption. The desorption rate, for the adsorption and desorption isotherm is a measure of the extent of desorption hysteresis. When the value of 100 $\%$ means that desorption proceeds as fast as adsorption and no hysteresis occurs. However, the value of less than $100 \%$ indicates that the rate of desorption is slower than the rate of adsorption and that hysteresis takes place. The value of desorption rate in this study spanned a range of 10-66 \% (Table-3), indication a hysteresis effect for all typical soils in Guanzhong basin.
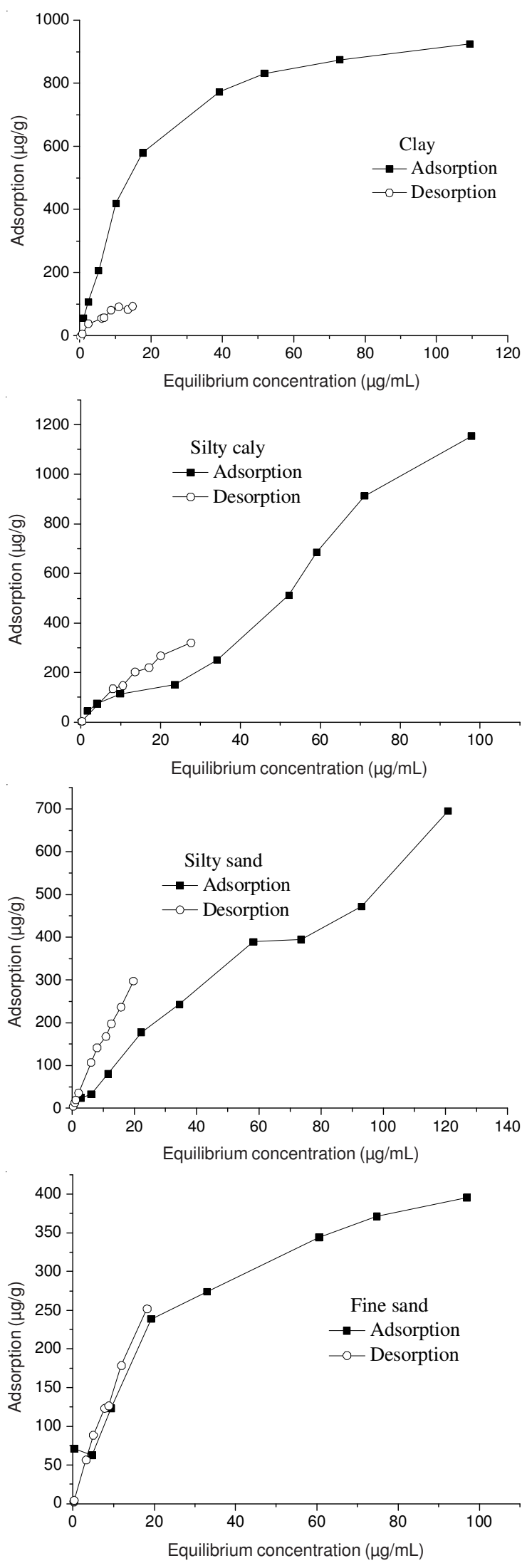

Fig. 2. Desorption hysteresis of soils 
Table- 3 showed that the adsorption coefficient of clay is the maximum and its desorption coefficient is the minimum, but the adsorption coefficient of silty sand and fine sand is the minimum and their desorption coefficient are the maximum. However, the adsorption coefficient and desorption coefficient of silty clay are in the middle, which illustrates the order of desorption hysteresis is clay $>$ silty clay $>$ silty sand and fine sand.

\begin{tabular}{|c|c|c|c|c|c|}
\hline \multicolumn{6}{|c|}{$\begin{array}{c}\text { TABLE-3 } \\
\text { DESORPTION RATE OF AMMONIUM NITROGEN }\end{array}$} \\
\hline Soil & $\begin{array}{c}\text { Adsorption } \\
\text { coefficient } \\
(\mathrm{L} / \mathrm{kg})\end{array}$ & $\begin{array}{c}\text { Desorption } \\
\text { coefficient } \\
(\mathrm{L} / \mathrm{kg})\end{array}$ & $\begin{array}{c}\text { Maximum } \\
\text { adsorption } \\
(\mathrm{mg} / \mathrm{kg})\end{array}$ & $\begin{array}{c}\text { Maximum } \\
\text { desorption } \\
(\mathrm{mg} / \mathrm{kg})\end{array}$ & $\begin{array}{l}\text { Desorption } \\
\text { rate }(\%)\end{array}$ \\
\hline Clay & 19.92 & 8.71 & 924.23 & 93.40 & 10.0 \\
\hline $\begin{array}{l}\text { Silty } \\
\text { clay }\end{array}$ & 12.37 & 12.37 & 1154.06 & 319.00 & 28.0 \\
\hline $\begin{array}{l}\text { Silty } \\
\text { sand }\end{array}$ & 5.43 & 15.07 & 694.41 & 297.35 & 43.0 \\
\hline $\begin{array}{l}\text { Fine } \\
\text { sand }\end{array}$ & 7.99 & 14.09 & 380.00 & 251.80 & 66.0 \\
\hline
\end{tabular}

Desorption hysteresis has been confirmed in desorption rate also. In particular, the desorption rate indicate the release of a pollutant adsorbed. The values of desorption rate for clay, silty clay, silty sand and fine sand were 10, 28, 43 and $66 \%$ respectively. The highest desorption rate was obtained from fine sand, which had the minimum adsorption, while the lowest desorption rate was obtained for clay, which had the minimum desorption (Table-3). According to the desorption rate of the four soils in Guanzhong basin, it was shown that the retardant capacity for ammonium nitrogen migration. The order of retardant capacity for clay, silty clay, silty sand and fine sand was strongest, stronger, weaker and weakest in sequence. The highest desorption rate and the weakest retardant capacity for ammonium nitrogen indicated that the migration rate would be significant in fine sand and lead to a increasing of the polluted risk for the shallow groundwater.

Effect of soil texture on ammonium nitrogen adsorptiondesorption: Soil clay mineral (illite, etc.), hydrous oxide (oxide of iron, manganese and aluminum) and organics are the key factors influencing the reaction rate and capacity of absorptiondesorption of ammonium nitrogen. The content of clay minerals such as illite, montmorillonite and chlorite in clay, silty clay, silty sand and fine sand was analyzed by X-diffraction. The content of clay minerals was depended on the soil texture. The contents of clay minerals for clay, silty clay, silty sand and fine sand are 27, 24, 14 and $7.5 \%$ respectively. The maximum adsorption fitted equation $\mathrm{y}=32.23 \mathrm{x}+185.92$ was found to be the most appropriate to fit the $\mathrm{X}$-diffraction data. The value (y) is stood for the maximum adsorption and the value (x) is stood for the percentage content of clay mineral. For the adsorption of ammonium nitrogen, the fitted equation had higher correlation efficient $\left(\mathrm{R}^{2}=0.819\right)$.

Table-1 showed that the value of organics in clay, silty clay, silty sand and fine sand are 56.54, 47.08, 29.44 and 10.0 $\mathrm{g} / \mathrm{kg}$ respectively. In all cases the fitted equations were linear equations to describe the ammonium nitrogen maximum adsorption, with correlation efficient $\left(\mathrm{R}^{2}\right)$ of 0.789 . The correlation between adsorption of ammonium nitrogen and clay mineral or organics was positive, indicating the extent of adsorption-desorption of ammonium nitrogen increases as the clay minerals and organics increases. It has been described that there was significant correlation between ammonium nitrogen adsorption and organics or organic-inorganic compound ${ }^{26}$.

Effect of pH on ammonium nitrogen adsorptiondesorption: The effect of solution $\mathrm{pH}$ on ammonium nitrogen adsorption by four typical soils was investigated. The results showed that the ammonium nitrogen adsorption by four soils all increased with increasing solution $\mathrm{pH}$. This behaviour is usually explained in the terms of joint action of ammonium salt hydrolysis action and ion-competitive adsorption, as a function of $\mathrm{pH}$. Since $\mathrm{NH}_{4}{ }^{+}$is weak acid alkali salt, the hydrolysis equation in solution gives:

$$
\mathrm{NH}_{4}{ }^{+}+\mathrm{H}_{2} \mathrm{O} \Leftrightarrow \mathrm{NH}_{3} \mathrm{H}_{2} \mathrm{O}+\mathrm{H}^{+}
$$

The behaviour is cation exchange indeed, as a function of ammonium nitrogen adsorbed-desorbed at the surface of clay mineral. This behaviour is ususlly explained $\mathrm{NH}_{4}{ }^{+}$from ammonium nitrogen adsorbed-desorbed exchanged with cation at the surface of clay mineral. The reaction is:

Colloidal Nucleus $\cdot \mathrm{M}^{\mathrm{n}+}+\mathrm{nNH}_{4}{ }^{+} \Leftrightarrow$ Colloidal Nucleus $\cdot \mathrm{NH}_{4}{ }^{+}+\mathrm{M}^{\mathrm{n}+}$ where, $\mathbf{M}^{\mathrm{n}+}$ stands for alkali metal, alkaline earth metal and hydrogen, etc. The exchange adsorption means the process that $\mathrm{NH}_{4}{ }^{+}$enters the colloidal nucleus. Desorption means the procedure that $\mathrm{NH}_{4}{ }^{+}$in colloidal nucleus enters into the solution.

The hydrolysis moving reverse and the concentration of $\mathrm{NH}_{4}{ }^{+}$increasing when $\mathrm{pH}$ was $<6$, the concentration of $\mathrm{H}^{+}$ increasing as $\mathrm{pH}$ decreases. And competitive capacity on adsorption point of $\mathrm{H}^{+}$is much stronger than $\mathrm{NH}_{4}{ }^{+}$, the adsorption of $\mathrm{NH}_{4}{ }^{+}$decreases. The concentration of $\mathrm{OH}^{-}$increasing when $\mathrm{pH}$ was $>7$ and the surface of clay minerals presented negative electricity which reduce the competitive adsorption of $\mathrm{H}^{+}$for $\mathrm{NH}_{4}{ }^{+}$, so the adsorption of $\mathrm{NH}_{4}{ }^{+}$is improved. Moreover, the ammonia concentration in solution dropped down $\mathrm{NH}_{4}{ }^{+}$for the ammonia formed and partly volatilized in alkali solution, so the adsorption of $\mathrm{NH}_{4}{ }^{+}$was adding ${ }^{27}$.

Effect of temperature on ammonium nitrogen adsorption-desorption: The effect of temperature on ammonium nitrogen adsorption-desorption by the silty sand was investigated. The results are shown in Fig. 3. The capacity of adsorptiondesorption by silty sand decreased with increasing temperature. But the effect of temperature on the ammonium nitrogen adsorption was more significant than the capacity desorption.

The ammonium nitrogen absorption is exothermic reaction, while the ammonium nitrogen desorption is endothermic

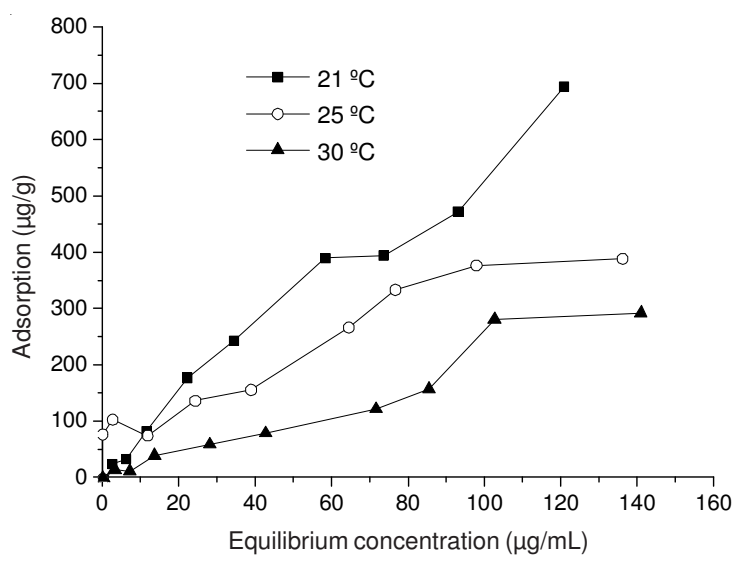




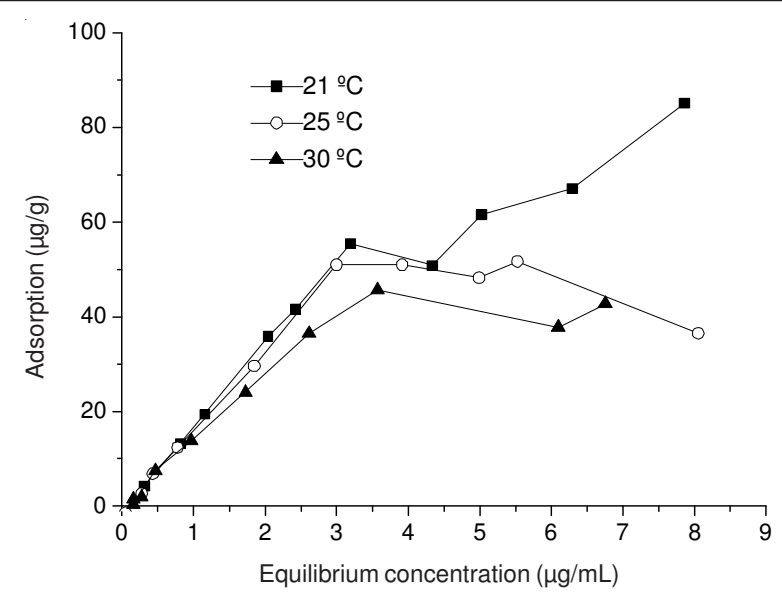

Fig. 3. Effect of temperature on ammonium nitrogen adsorption-desorption

reaction, so the adsorption decreases with the increasing of temperature. To determine the degree of influence of temperature on adsorption-desorption, Gibbs standard enthalpy change $\left(\Delta \mathrm{H}^{\circ}\right)$ analyses of ammonium nitrogen adsorption-desorption were performed. The absolute $\Delta \mathrm{H}^{\mathrm{o}}$ value for ammonium nitrogen adsorption was $75.73 \mathrm{~kJ} / \mathrm{mol}$ and the $\Delta \mathrm{H}^{\mathrm{o}}$ value for ammonium nitrogen desorption was $11.22 \mathrm{~kJ} / \mathrm{mol}$. Moreover, the absolute value $\Delta \mathrm{H}^{\circ}>20 \mathrm{~kJ} / \mathrm{mol}$ of adsorption is the joint action of the ion exchange, chemical bond and hydrogen bond according to Zhang and $\mathrm{Li}^{28,29}$ and the value $\Delta \mathrm{H}^{\circ}<20 \mathrm{~kJ} / \mathrm{mol}$ of desorption is the joint action of the Van der Waals forces, dipole moment and hydrogen bond according to Huang and Zhou $^{30,31}$. For this reason, the ammonium nitrogen absorption process could not totally reversible.

\section{Conclusion}

By using the batch equilibrium experiments, the adsorption-desorption of ammonium nitrogen was determined in typical soils collected in Guanzhong basin of China. The Langmuir model was found to be the most appropriate to fit experimental data and then to describe the ammonium nitrogen adsorption process onto clay and fine sand. Henry model can describe the ammonium nitrogen adsorption process onto silty clay and silty sand accurately. The adsorption coefficient of ammonium nitrogen for four typical mediums follows the sequence clay $>$ silty clay $>$ fine sand $>$ silty sand.

The isothermal desorption curve of ammonium nitrogen of silty clay, silty sand and fine sand were fitted to the Henry model, expect for the clay which the Langmuir Ext1 model fitted better. The desorption coefficients order of desorption coefficients of different soils are silty sand $>$ fine sand $>$ silty clay $>$ clay respectively. The values of desorption rate for clay, silty clay, silty sand and fine sand were 10, 28, 43 and $66 \%$ indicated that the order of retardant capacity for clay, silty clay, silty sand and fine sand was strongest, stronger, weaker and weakest in sequence.

The correlation between ammonium nitrogen adsorption and the content of clay minerals or organics in soils was found to be positive. The effect of solution $\mathrm{pH}$ on ammonium nitrogen adsorption by four typical soils was significant, for in the terms of joint action of ammonium salt hydrolysis action and ioncompetitive adsorption, as a function of $\mathrm{pH}$. The capacity of adsorption-desorption by silty sand decreased with increasing temperature. The absolute value $\Delta \mathrm{H}^{\circ}>20 \mathrm{~kJ} / \mathrm{mol}$ of adsorption indicated that the joint action of the ion exchange, chemical bond and hydrogen bond. And the value $\Delta \mathrm{H}^{\circ}<20 \mathrm{~kJ} / \mathrm{mol}$ of desorption indicated that the joint action of the Van der Waals forces, dipole moment and hydrogen bond.

\section{ACKNOWLEDGEMENTS}

This work was supported by the National Natural Science Foundation of China $(41102150,41002086)$ the Special Fund for Basic Scientific Research of the Central Colleges, Chang'an Unversity, China (CHD2010JC029, CHD2010JC051) and the Major Science and Technology Program for Water Pollution Control and Treatment of China (2009ZX07212-002). The authors thank the Key Laboratory of Western Mineral Resources and Geological Engineering of Ministry of Education, Chang'an Unversity, China.

\section{REFERENCES}

1. H.S. Hong, J.L. Huang and W.Z. Cao, The Agricultural Nonpoint Source Pollution Mechanism and Control in Nine Longjiang Drainage, Science Press, Beijing (2008).

2. V.M. Chowdary, N.H. Rao and P.B.S. Sarma, J. Agric. Water Manag., 75, 194 (2005).

3. W. Dejonckheere, W. Steurbaut and S. Drieghe, J. AOAC Int., 79, 97 (1996).

4. E. Neidert and H.W. Saschenbrecker, J. AOAC Int., 79, 549 (1996).

5. B. Lars and B. Nils, J. Plants Soil, 93, 24 (1986).

6. X.Z. Gao, C.B. Ma and S.L. Chen, J. Chem. Fertil. Ind., 3, 3 (2003).

7. K. Inubushi, M.A. Barahona and K. Yamakawa, J. Biol. Fertil. Soils, 29, 401 (1999)

8. X.Y. Song, G.X. Yin and Y.X. He, J. Safety Environ., 6, 136 (2006).

9. V.Z. Antonopoulos, Water Resour. Manag., 7, 237 (1993).

10. A.H. Wolfe and J.A. Patz, Ambio, 31, 120 (2002).

11. Y.W. Lee, Risk Assessment and Risk Management for Nitrate-Contaminated Groundwater Supplies, University of Nebraska, Lincoln, Nebraska (1992).

12. Y.A. Dong, Z.L. Shen and Z.X. Zhong, Acta Scient. Circumst., 19, 610 (1999).

13. C.W. Fetter, Contaminant Hydrogeology, Prentice-Hall, Englewood Cliffs, NJ (1999).

14. T. Thayalakumaran, K.L. Bristow and B. Philip, J. Agric. Water Manag., 95, 103 (2008).

15. L.H. Zhai, H.L. Liu and H.D. Xu, J. Environ. Sci., 28, 1770 (2007).

16. S. Zhang, C.Y. Zhang and S.Y. Ye, Acta Geosicien. Sin., 24, 187 (2003).

17. X.H. Luan, C. Wang and L. Zhu, J. Hohai Univ. (Nature Sci.), 24, 51 (1996).

18. Z.P. Li and X.G. Chen, The Effect of Discharging Pollution River on Groundwater, Yellow River Water Conservancy Press, Zhenzhou (2006).

19. W. Yang, Y. Guo and Y. Wang, J. Shengyang Jianzhu Univ. (Nature Sci.), 23, 826 (2007).

20. Dontsova, M. Katerina and L. Nort, Soil Sci. Soc. Am. J., 69, 1225 (2005).

21. V. Rasiah, J.D. Armour and N.W. Menzies, J. Environ. Qual., 123, 205 (2004).

22. D.Z. Sun, X.Q. Li and X.F. Pan, J. Environ. Sci. Technol., 30, 16 (2007).

23. OECD Guidelines for the Testing of Chemicals, Adsorption/desorption Using a Batch Equilibrium Method OECD Test Guideline, OECD Publications, Paris (2000).

24. J.K. Rosenfeld, J. Limnol. Oceanogr., 24, 356 (1979).

25. M. Liu, L.J. Hou and S.Y. Xu, Acta Oceanol. Sin., 27, 60 (2005).

26. C.D. Boatman and J.W. Murray, J. Limnol. Oceanogr., 27, 99 (1984).

27. S.K. Yang, W.K. Wang and X. Li, J. Xi'an Eng. Univ., 22, 69 (2000).

28. J.Q. Zhang and Y.H. Dong, Acta Pedolog. Sin., 45, 978 (2008).

29. H.T. Li, Y.C. Jiao and M.C. Xu, Polymer, 45, 181 (2004).

30. J.G. Huang, M.C. Xu and Z.Q. Shi, Chin. Chem. Lett., 14, 914 (2003).

31. Y. Zhou, J.F. Zhou and L.M. Tao, Res. J. Environ. Sci., 22, 521 (2009). 